\title{
Commission for the Management \& Application of Geoscience Information (CGI)
}

\author{
http://www.cgi-iugs-org/
}

\begin{abstract}
An introduction to CGI
Information in general and digital information in particular, underpins all of the IUGS strategic objectives. CGI is helping to address a growing need to improve the quality and range of both information content and the applications that are used to acquire, analyse, process and disseminate geoscience data. It will do this by the exchange of knowledge and best practice and the support for standards. CGI is a new (strictly speaking, re-activated) Commission, founded by the IUGS in late 2002 following the demise of an earlier information Commission, COGEOINFO. Early tasks for CGI were to establish its objectives, set up its structure and modus operandi, elect its Council and establish a web presence. The new Commission was formally ratified by the IUGS at the IGC in Florence in 2004 and also held its first full Open Meeting there. For this meeting new Statutes were produced and agreed, elections were held for the Council, the CGI web site was completely overhauled and refreshed, flyers were designed and distributed, and invitations to the Open Meeting were mailed to over 1500 people worldwide - the aim being to make sure that as many people as possible would be aware of our existence.
\end{abstract}

\section{CGI Aims}

- Help in exchanging knowledge on geoscience information and systems

- Support dissemination of best practice in geoscience information

- Encourage the development of geoscience information standards

- Play a full part in the international geoscience information community and represent IUGS on geoscience information matters

- Bring together individuals and organisations with an interest in the management and application of geoscience information

\section{Membership and organizational structure}

At the time of writing 138 people have registered to be members of CGI, representing over 49 countries and the five continents. The major increase in membership came as a result of the publicity associated with the launch of CGI at the IGC, but we continue to grow steadily. CGI operates through a Council of 10 people. The Chair, Secretary General and Treasurer of the Council form an Executive sub-committee. Prof. Jean-Paul Cadet, President of the Commission of the Geological Map of the World (CGMW), is our contact on the IUGS Executive. Working Groups on specific issues and Regional Groups focussing on region-related subjects may be established and we have already done this. There is also the possibility to establish special interest groups and, subsequently, build Sub-Commissions (see Figure 1).

\section{Council members and officers}

Kristine Asch (Chair)

Bundesanstalt für Geowissenschaften und Rohstoffe

Stilleweg 2

D - 30655 Hannover

Germany

Telephone: +495116433324

Fax: +49 5116433782

E-mail: Kristine.Asch@bgr.de

\author{
Ian Jackson (Secretary General) \\ British Geological Survey \\ Kingsley Dunham Centre \\ Keyworth \\ Nottingham NG12 5GG \\ UK \\ Telephone: +441159363214 \\ Fax: +44 1159363269 \\ E-mail: ij@bgs.ac.uk
}

Max Fernandez-Alonso (Treasurer)

Departement Geologie

Koninklijk Museum voor MiddenñAfrika

Leuvensesteenweg, 13

3080 Tervuren

Belgium

Telephone: +32 2769.5431

Fax: +32 2769.5432

E-mail: mfernandez@africamuseum.be

Simon Cox

CSIRO Exploration \& Mining

26 Dick Perry Avenue

Kensington WA 6151

Australia

Telephone: +61 (8) 64368639

Fax: +61 (8) 64368555

E-mail: Simon.Cox@csiro.au

Anna-Karren Nguno

Geological Survey of Namibia

1 Aviation Road

Private Bag 13297

Windhoek

Namibia

Telephone: +264 61284811

Fax: +264 61249144

E-mail: anguno@mme.gov.na

François Robida

BRGM

3 avenue $C$ Guillemin

BP 6009 - 4506

France

Telephone: +33238643121

E-mail: f.robida@brgm.fr

John Broome

Earth Science Sector

601 Booth Street

Ottawa, Ontario

Canada

K2R 1G2

Telephone: +1 6139956914

Fax: +1 6149952339

E-mail: broome@nrcan.gc.ca

Dave Soller

US Geological Survey

926A National Center

Reston VA,20192

USA

Telephone: +1 7036486907

E-mail: drsoller@usgs.gov 


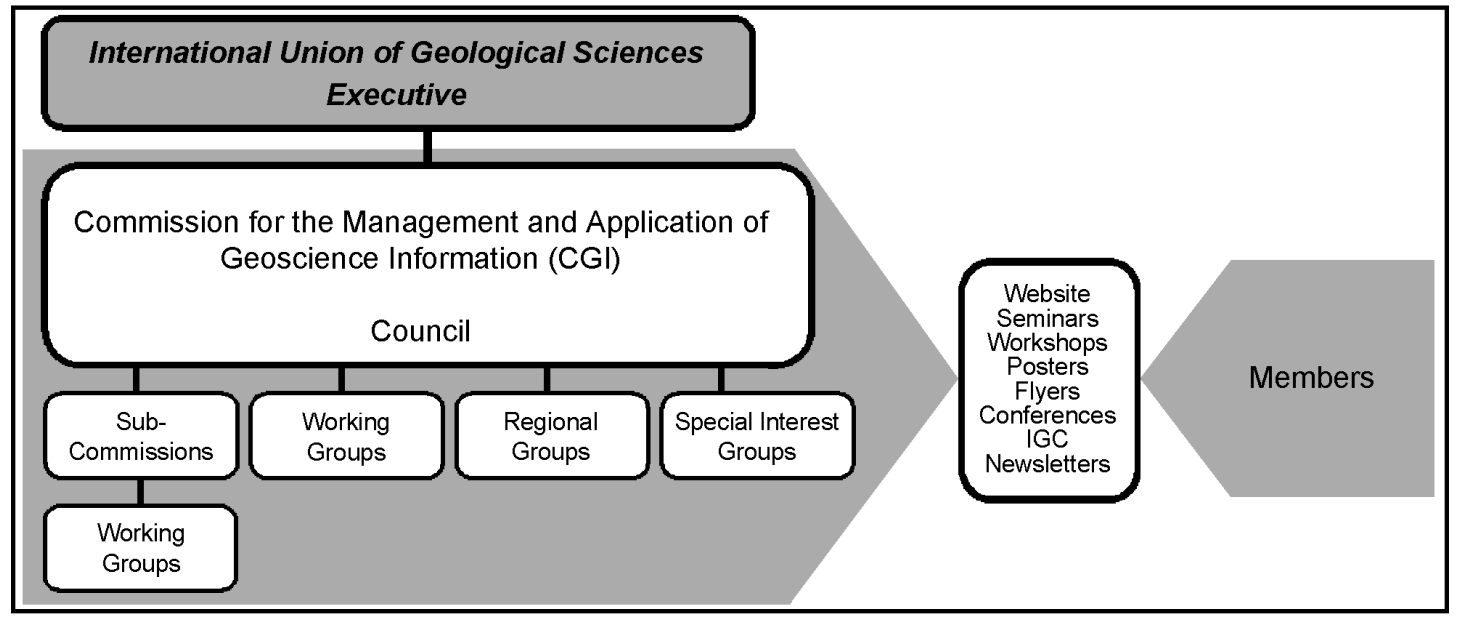

Figure 1 The CGI organizational structure.

Sergei Cherkasov

Vernadsky SGM RAS

11-2 Mokhovaya Str

Moscow 125009

Russia

Telephone: +7 952034667

Fax: +7 952035287

E-mail: sergy@sgm.ru

\section{Koji Wakita}

Institute of Geoscience

Geological Survey of Japan

1-1-1 Higashi

Tsukuba

Ibaraki 305-8567

Japan

Telephone: +81-298-61-24694

Fax: +81-298-61-3742

E-mail:koji-wakita@aist.go.jp

\section{Action Plan for 2004-2008}

The CGI Council spent some time during 2005 reviewing the Action Plan of CGI in light of progress and experience during its first full year. The revised action points are summarized below:

- Understand and map the mandates and activities of international geoscience bodies;

- Catalyze productive alliances between geoscience information bodies;

- Refine the multi-lingual geoscience thesaurus;

- Develop a framework for CGI ratification of geoscience information standards;

- Promote international use of data exchange standards;

- Facilitate organisation of relevant outreach workshops.

The prime intention has been to make these actions useful, practical and achievable and in line with the actual resources which CGI is likely to have at its disposal. In addition to the specific actions within our plan we hope to make a contribution to the 2008 IGC and members of Council are currently involved in the formulation of the INSPIRE Directive - a proposal to create a Spatial Data Infrastructure for Europe. We have completed the survey of geoscience information bodies which exist across the world-their roles, activities and scope, and have released the first version of the database on the CGI website. 27 groups are now listed and as others become known to us we are updating the database. We have already made contact with several of these groups to try and establish appropriate linkages and alliances.

One of the major aspirations of CGI is to organise Outreach workshops where information and experiences can be exchanged and knowledge transferred. Outline plans for such workshops have been developed and we are currently working with the IUGS and the organizers of the "21st Colloquium on African Geology in Maputo" to organize a "pre-Outreach Workshop" seminar to improve and refine our plans. The Namibian Geological Survey has agreed to act as hosts and local organisers for the first major workshop. However, such workshops will require substantial funding, which is currently beyond the means of CGI. For this reason we are approaching a number of potential sponsors. Amongst the first of these was UNESCO, represented by Robert Missotten. UNESCO was exceedingly positive about the initiative and have agreed to provide their support; additionally they voted funds in 2005 for CGI to create a brochure and prospectus to take the workshop concept forward. CGI is also setting aside the majority of its own financial reserves to leverage money from others and co-fund the workshop.

CGI have been in contact with the Chair and Organising Committee of the IGC 2008 in Norway offering to assist in organising and coordinating a major multi-session special symposium on geoscience information at IGC 2008 . We have proposed a basic structure, which can act as a framework in which to fit, in a coherent way, all the geo-information sessions.

INSPIRE is an upcoming Directive of the European Commission. It will put in place regulations within all EU countries in order to build a spatial data infrastructure to improve the sharing of and access to information across Europe. Geology is one of the data themes included in INSPIRE. CGI are playing a part in the formulation of the Directive in several ways. We are active in the EuroGeoSurveys INSPIRE Working Group; one of our Council is a member of the EC groups drafting the regulations; and CGI work on a data model and GeoSciML schema has been accepted as a reference project to assist in drafting the regulations.

\section{CGI's Working Groups}

\section{Geoscience Data Model International Collaboration (gDMIC) Working Group}

The specific objectives of this CGI working group are to:

- develop a conceptual model of geoscientific information drawing on existing data models;

- implement an agreed subset of this model in an agreed schema language;

- implement an XML/GML encoding of the model subset;

- develop a testbed to illustrate the potential of the data model for interchange;

- identify areas that require standardised classifications in order to enable interchange. 


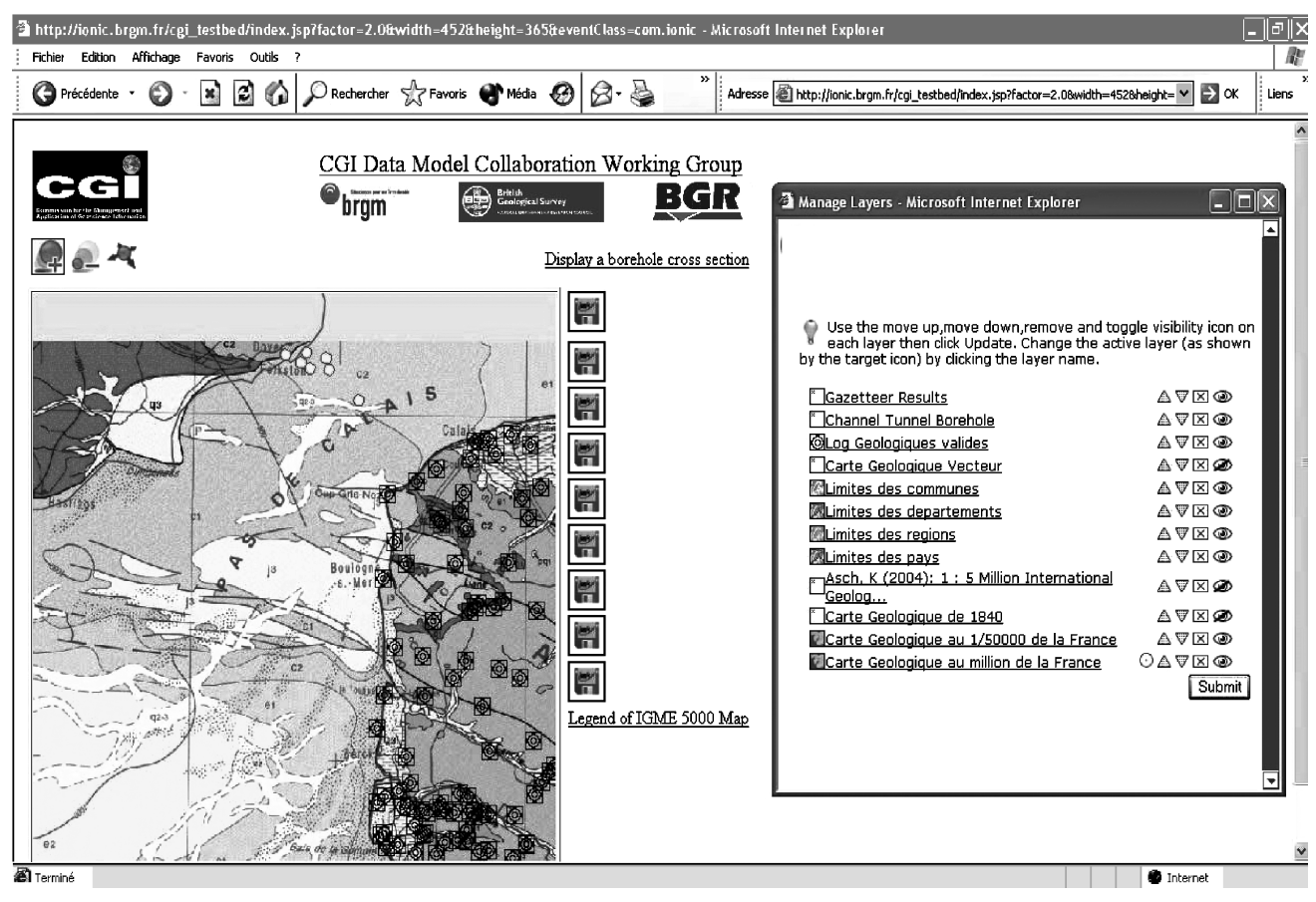

Figure 2 The CGI gDMIC testbed web site.

The group met in Ottawa in August and work has progressed well. News of the Testbed (see Figure 2) has been released on the CGI website (http://www.bgs.ac.uk/cgi_web/news.html). The work, which is attracting considerable interest from organisations around the globe, continues to gather pace and the Testbed is expected to be fully functional in Spring 2006.

The Testbed will initially be exchanging data from at least eight Geological Surveys around the world. The developing model, including both the UML and XML (GeoSciML) schemas includes:

- Geologic Units

- Structure Objects (restricted to faultsand contacts at present)

- Boreholes

- Metadata (both discovery and feature level)

- Earth Material (lithology, etc)

- Geologic Age

- Geologic Time

- Vocabularies (structure)

A first draft of the data model and schemas have been completed and current work is concentrating on mapping data from the internal data models of the participating organisations to the common data model and thus generating instance schema documents. The first release of GeoSciML had been completed before 31 December 2005 and the CGI site was updated with the details.

\section{Multi-lingual Thesaurus Working Group (MTG)}

The task of this Working Group is to review and produce an up-todate and coherent version of the Multi-lingual Thesaurus for the geosciences. The current thesaurus has been in existence for more than a decade, but it is widely regarded as inconsistent, incomplete and inaccurate. The group has already undertaken a review of the existing thesaurus and during 2005, met in Nottingham and Warsaw to produce a plan for the work that needs doing to deliver a worthwhile and viable multilingual thesaurus. A major issue is the considerable resources that this work will require and so the Group have prepared a proposal and bid for European Commission funding (to the "e-Contentplus" programme). If the bid proposal fails the plan will still form the framework for the work of the Group but obviously the work will be stretched over a significantly longer period.

Fax: +44 1159363269

\section{Regional Working Groups}

Regional CGI Working Groups were proposed at the inaugural CGI meeting in Florence. The first of these (the Regional Working Group for East and Southeast Asia) was initiated in late November 2005. A second group for Russia has also been proposed. The Regional Working Group for East and Southeast Asia was proposed at the CGI Council Meeting in Toronto and has the following main objectives:

- To exchange information and opinions on geological information and its standards;

- To disseminate CGI activities to the region;

- To review the activities in geoinformation and geological standards;

- To get more CGI members in the region.

The preliminary meeting was held on 25th November 2005 in

Bangkok and the work of the group will be linked to the work of the Coordinating Committee for Coastal and Offshore Geoscience Programmes in East and Southeast Asia (CCOP). CCOP is an intergovernmental organization for the geological community of East and Southeast Asian region.

\section{Communication}

CGI is still a very new Commission and because of this we continue to put a lot of effort into making people aware of our existence and purpose! Members of the Council have given presentations on CGI and its work at conferences and workshops around the globe. Our website http://www.cgi-iugs.org/ is a particularly prominent part of the CGI communication strategy: it is regularly updated and kept dynamic by the CGI Secretariat. In addition to containing all the documentation about the Commission, it has news about related projects, events and web resources and it provides space for technical information posting and exchange. In 2005 the website received approximately 30000 visitor sessions (as opposed to just hits), that is about 80 visitors per day spending more than 15 minutes each on the site.

\section{Dr. Kristine Asch}

Bundesanstalt für Geowissenschaften und Rohstoffe

(Federal Institute for Geosciences and Natural Resources)

Stilleweg 2

D - 30655 Hannover

Germany

Telephone: +495116433324

Fax: +495116433782

E-mail:Kristine.Asch@bgr.de

\section{Ian Jackson}

British Geological Survey

Kingsley Dunham Centre

Keyworth

Nottingham NG12 5GG

$U K$

Telephone: +441159363214

E-mail:ij@bgs.ac.uk 